\section{Update on strategies limiting iatrogenic hypoglycemia}

\author{
Aldo Bonaventura ${ }^{1}$, Fabrizio Montecucco ${ }^{1,2,3}$ and Franco Dallegri ${ }^{1}$ \\ ${ }^{1}$ Department of Internal Medicine, First Clinic of Internal Medicine, University of Genoa School of Medicine, \\ IRCCS Azienda Ospedaliera Universitaria San Martino - IST Istituto Nazionale per la Ricerca sul Cancro, Genoa, Italy \\ ${ }^{2}$ Division of Cardiology, Foundation for Medical Researches, Department of Medical Specialties, University of \\ Geneva, Geneva, Switzerland \\ ${ }^{3}$ Division of Laboratory Medicine, Department of Genetics and Laboratory Medicine, Geneva University Hospitals, \\ 4 rue Gabrielle-Perret-Gentil, Avenue de la Roseraie 64, 1205 Geneva, Switzerland
}

\author{
Correspondence \\ should be addressed \\ to F Montecucco \\ Email \\ fabrizio.montecucco@ \\ unige.ch
}

\begin{abstract}
The prevalence of type 2 diabetes mellitus (T2DM) is increasing all over the world. Targeting good glycemic control is fundamental to avoid the complications of diabetes linked to hyperglycemia. This narrative review is based on material searched for and obtained via PubMed up to April 2015. The search terms we used were: 'hypoglycemia, diabetes, complications' in combination with 'iatrogenic, treatment, symptoms.' Serious complications might occur from an inappropriate treatment of hyperglycemia. The most frequent complication is iatrogenic hypoglycemia that is often associated with autonomic and neuroglycopenic symptoms. Furthermore, hypoglycemia causes acute cardiovascular effects, which may explain some of the typical symptoms: ischemia, QT prolongation, and arrhythmia. With regards to the latter, the night represents a dangerous period because of the major increase in arrhythmias and the prolonged period of hypoglycemia; indeed, sleep has been shown to blunt the sympatho-adrenal response to hypoglycemia. Two main strategies have been implemented to reduce these effects: monitoring blood glucose values and individualized HbA1c goals. Several drugs for the treatment of T2DM are currently available and different combinations have been recommended to achieve individualized glycemic targets, considering age, comorbidities, disease duration, and life expectancy. In conclusion, according to international guidelines, hypoglycemia-avoiding therapy must reach an individualized glycemic goal, which is the lowest HbA1c not causing severe hypoglycemia and preserving awareness of hypoglycemia.
\end{abstract}

Endocrine Connections (2015) 4, R37-R45

\section{Introduction}

In diabetes mellitus (DM), hypoglycemia is the most feared adverse effect of glucose-lowering drugs (GLDs) such as insulin and secretagogues (sulphonylureas (SUs) and glinides). Iatrogenic hypoglycemia (IH) involves reduced motivation and compliance with achieving good glycemic control that minimizes the risk of diabetic complications, with a consequent increase in cardiovascular (CV) and neurological morbidities. In this review, based on the material searched for and obtained via PubMed up to April 2015 (search terms: 'hypoglycemia, diabetes, complications' in combination with 'iatrogenic, treatment, symptoms'), we will provide an overview of this growing problem and some advice on therapy. 


\section{Epidemiology}

The incidence of hypoglycemia varies greatly between different studies, and it is hard to compare epidemiological data due to differing study designs, populations, and definitions of hypoglycemia. On the basis of the available data, the frequency of severe hypoglycemia in adults with type $1 \mathrm{DM}$ (T1DM) ranges from 0.2 to 3.2 episodes per patient per year $(1,2)$ and from 0.1 to 0.7 in insulin-treated T2DM patients (2). In patients with impaired awareness of hypoglycemia (IAH), it is more difficult to have a precise estimation of the incidence without a consultation with patients' relatives (3). Mild hypoglycemia is hard to identify because patients rarely have an accurate recall of the event lasting more than 1 week (4); the average incidence is 1-2 episodes per patient per week in T1DM $(4,5,6,7)$ and $0.3-0.7$ episodes per patient per week in insulin-treated T2DM $(6,7)$. The highest rate of severe hypoglycemic episodes during insulin therapy occurs during the first trimester of pregnancy in women with T1DM (8). The frequency of hypoglycemia in T2DM patients is lower than in T1DM ones; however, the longer they are treated with insulin, the more often they may experience hypoglycemic events, concomitant with a slow, progressive decline in the functioning of $\beta$-cells $(2,9)$.

\section{Definition}

Classically, hypoglycemia is defined by the Whipple triad: the presence of low blood sugar; autonomic and neuroglycopenic symptoms; and reversal of the symptoms after restoration of the blood glucose level to normal (10). This classical definition was updated by international associations with different glycemic thresholds:

1) European Medicines Agency (EMA): $70 \mathrm{mg} / \mathrm{dl}$ (3.9 mmol/1) (11).

2) American Diabetes Association (ADA): $70 \mathrm{mg} / \mathrm{dl}$ (3.9 mmol/l) (12).

3) Canadian Diabetes Association (CDA): $72 \mathrm{mg} / \mathrm{dl}$ $(4.0 \mathrm{mmol} / \mathrm{l})(13)$

The Workgroup on Hypoglycemia of the American Diabetes Association (ADA) included in the definition of hypoglycemia 'all episodes of an abnormally low plasma glucose concentration that expose the individual to potential harm' (10). This extended definition, not anchored to a number, takes the variability of the hypoglycemia threshold among individuals into account: symptomatic glucose blood levels tend to become progressively lower after repeated hypoglycemic episodes
$(14,15,16)$, while they are higher in patients with poor glycemic control and presenting with rare hypoglycemic events (17).

Moreover, standard classifications include confirmed, severe, and nocturnal hypoglycemia. Confirmed hypoglycemia is an event for which a blood glucose measurement below the defined threshold is available; a severe event requires the assistance of another person; a nocturnal event occurs during the night, regardless of whether the individual is awake or asleep, considering 'nocturnal' to be during the period from bedtime until waking up (10).

\section{Pathophysiology of hypoglycemia}

Glucose is the primary source of energy for many organs (i.e., the brain) that are vulnerable to low blood glucose levels. In order to protect the brain, a variety of physiological mechanisms are activated to minimize the effects of hypoglycemia $(18,19)$. The initial reaction is the cessation of insulin secretion at a blood glucose threshold of $\sim 83 \mathrm{mg} / \mathrm{dl}(\sim 4.6 \mathrm{mmol} / \mathrm{l})$ (20), followed by counterregulatory hormone responses (i.e., glucagon and epinephrine, starting at $68.4 \mathrm{mg} / \mathrm{dl}(3.8 \mathrm{mmol} / \mathrm{l}))$ and cognitive and symptomatic changes $(20,21,22)$. Despite initial common mechanisms, the pathophysiology of hypoglycemia differs between T1DM and T2DM patients.

\section{T1DM}

In T1DM, because of the absence of working $\beta$-cells, circulating levels of exogenous insulin cannot decrease when plasma glucose levels decline, so this first-line defense against hypoglycemia is lost (23). The secondline defense, i.e. increase of glucagon levels, is lost too, and this is believed to be a signaling defect depending on endogenous insulin deficiency (24). Therefore, T1DM patients critically depend on the third-line defense consisting in an increase in epinephrine levels, which stimulates hepatic glycogenolysis and gluconeogenesis and limits glucose utilization by insulin-sensitive tissues.

\section{T2DM}

As previously underscored, the incidence of IH is lower in T2DM patients than in T1DM patients $(6,7)$. These epidemiological data indicate that glucose counter-regulatory mechanisms are conserved in T2DM patients, at least in the early phases of the disease. In addition, in T2DM patients, treated not only with insulin but with SUs, the risk of hypoglycemia further increases. The net result of the hormonal response is the prolongation of hypoglycemia, as 
the limited glucose utilization delays the recovery of glucose after a hypoglycemic episode. Actually, in T2DM patients with progressive insulin deficiency, IH becomes a problem very similar to that of T1DM patients. In this subcategory of T2DM patients, glucagon response to hypoglycemia is virtually absent and the glycemic thresholds are shifted to lower plasma glucose concentrations after a recent hypoglycemic episode (25).

\section{Clinical presentation}

Hypoglycemia causes symptoms that can be classified into two main categories: neurogenic or autonomic and neuroglycopenic $(21,22)$. The first symptoms are caused by the physiological responses to low glucose concentrations and include trembling, sweating, anxiety, and hunger. The neuroglycopenic symptoms derive from glucose deprivation in the central nervous system and include cognitive impairment, confusion, behavioral changes, loss of consciousness, and, in severe cases, even death.

\section{Risk factors}

Besides insulin and SUs, quinolones, heparin, $\beta$-blockers, and trimethoprim-sulfamethoxazole have been also reported to induce hypoglycemia (26). In particular, among glipizide and gliburide users, exposure to ciprofloxacin, clarithromycin, levofloxacin, metronidazole, and sulfamethoxazole-trimethoprim has been shown to increase hypoglicemic episodes, of which nearly $40 \%$ required hospitalization (27). Inadequate, delayed, or missed meals; exercise; hot weather; and use of recreational drugs or excessive alcohol consumption might be associated with IH. Age-related impairment of the counterregulatory hormone responses could be also associated with IH $(20,22)$. Other factors influencing the risk of hypoglycemia might include marked changes in body weight and renal or liver dysfunction $(28,29,30)$. Depression was also found to be associated with the risk of severe hypoglycemia (31). Recurrence of hypoglycemia may occur due to the development of autonomic failure (hypoglycemia-associated autonomic failure (HAAF)) (32). This condition can be improved after three days of hypoglycemia avoidance, whereas 2-3 weeks without episodes can restore hypoglycemia awareness and improve the neuroendocrine responses to hypoglycemia (33).

Hypoglycemia unawareness is also a great risk factor for its occurrence. It is defined as the onset of hypoglycemia before the appearance of autonomic warning symptoms and presents clinically as the patient's inability to perceive hypoglycemic symptoms $(34,35)$; the reduced magnitude of counter-regulatory responses to subsequent hypoglycemic episodes involves their starting at increasingly lower glucose concentrations. In many patients, there is a problem of undisclosed hypoglycemia, as they do not discuss hypoglycemia with their physicians, mainly because they feel hypoglycemia to be a private issue, or because they don't feel comfortable sharing with others $(36,37)$. A few patients do not understand the importance of hypoglycemia, or they are concerned about losing their driver's licence or job if they report a serious or frequent episode (or episodes) of hypoglycemia (38).

\section{Hypoglycemia and the CV system}

Hypoglycemia has been shown to be associated with an inappropriate increase in catecholamine levels and peptides, such as endothelin, markers of endothelial dysfunction and platelet activation, and atherosclerotic inflammation $(39,40,41,42)$. The results of other studies have revealed an acute increase in leukocyte mobilization and clotting factors during hypoglycemia (39, 40, 41, 42, $43,44)$. The levels of inflammatory mediators and prothrombotic changes remain elevated from $24-48 \mathrm{~h}$ to 1 week (45) after restoration of normoglycemia (41).

During hypoglycemia, arteries are more elastic so that central arterial pressure falls, even if with aging the arterial wall stiffness attenuates the normal arterial response (46). Moreover, arterial stiffness in long-standing diabetic patients accelerates the return of the reflected systolic wave generated during myocardial contraction, potentially interfering with coronary perfusion (47).

Hypoglycemia might affect cardiac repolarization (48) and leads to EKG changes, including altered ST-segment and T-wave morphology and QT interval prolongation (49). The latter is thought to be a possible mechanism leading to fatality during CV events, being precipitated by increased circulating levels of cathecolamines and hypokalemia $(50,51)$, even if hypokalemia does not always play an important role during severe hypoglycemia (52). However, hypoglycemia at admission was associated with increased 30-day mortality in acute myocardial infarction patients with or without T2DM (53). Insulintreated T2DM patients with a history of either CV disease or two CV risk factors commonly show hypoglycemia during the night, associated with possible ischemic (T-wave flattening) and repolarization (increased QT intervals corrected for heart rate) alterations, and other cardiac arrhythmias (54). During nocturnal hypoglycemia there is an eightfold increase in bradycardia and a fourfold 
increase in atrial ectopy when compared with daytime hypoglycemia. Sleep has been shown to blunt the sympatho-adrenal response to hypoglycemia (55), contributing to the long duration and greater severity of nocturnal hypoglycemia; the proposed mechanism is a disproportionate parasympathetic phase leading to bradyarrhythmias and ectopic pacemakers.

\section{Hypoglycemia and the brain}

Domains involved in attention-demanding, rapid responses, complex thought processes, and multitasking are affected $(56,57)$. The time period before complete cognitive recovery after a hypoglycemic episode is reached can exceed $60 \mathrm{~min}$ and is influenced by the awareness of hypoglycemia (58). Other neurologic manifestations range from irritability to seizures and coma. Moreover, in T1DM adolescents epileptiform activity during hypoglycemia is more frequently observed and theta waves persist after restoration of normoglycemia (59). The augmented blood flow to the frontal cortex during acute hypoglycemia in order to supply the most vulnerable part of the brain persists during normoglycemia, too, leading to autoregulation disruption $(60,61)$. As a result, the risk of cerebral ischemia during any condition of hemodynamic stress is increased (59). Transient ischemic attacks and hemiplegia can present during hypoglycemia, especially in the elderly (62).

\section{Strategies to limit hypoglycemia and its complications}

The modulation of the intensiveness of glucose lowering in T2DM is essential in order to determine optimal HbA1c targets related to patient/disease features, disease duration, life expectancy, comorbidities, established vascular complications, and patient attitude (63). In the Position Statement by the ADA and the European Association for the Study of Diabetes, it is highlighted that optimal management of T2DM takes into account the different comorbidities of patients, including hypoglycemia that is considered similarly to other conditions, such as coronary artery disease, heart failure, renal and liver disease, and dementia (63). A report of a workgroup of the ADA and the Endocrine Society illustrates the principal measures required in order to minimize hypoglycemia (64). The measures recommended to limit iatrogenic hypoglycaemia are summarized in Fig. 1.

The first step is to limit the hypoglycemic episodes, since this approach can completely restore hypoglycemia awareness in diabetes patients, as previously described (33). In order to follow the glycemic trend during the day, selfmonitored blood glucose (SMBG) is very useful and its benefit has been reasonably established in insulin-treated patients. This strategy allows patients to identify hypoglycemia and hyperglycemia and get immediate feedback about the effect of food choices, stress, activity, and insulin dosing on glucose levels. In addition, patients can better determine, together with clinicians, if a medication adjustment is needed. SMBG can help identify recurrent hypoglycemia even in patients with acceptable HbA1c (65). Frequency and timing of SMBG depend on glycemic control and current treatment. Some potential limitations of appropriate use of SMBG might be related to lack of disease knowledge as well as logbook and economic barriers (66). Patient compliance can be improved through decreasing the sample amount, alternate site testing, and elimination of the need for coding, while patients with disabilities may benefit from preloaded strips and audio reporting. A structured SMBG program improves glycemic control and facilitates more timely and aggressive therapeutic changes (67).

Furthermore, it is fundamental to educate patients and their relatives about the treatment of DM and the management of hypoglycemia, even if the provision of basic information about it can be sometimes neglected or might not be comprehended by some patients. For that reason, it is important for clinicians to regularly reinforce these concepts $(68,69)$. Psychologically based educational programs are useful to improve the patients' accuracy in detecting hypoglycemia (70). Other approaches also target dietary education and flexible insulin dosing strategies $(71,72)$.

Despite refinements in insulin therapy, the frequency of hypoglycemia did not change in T1DM patients (73). This aspect was possibly due to stricter glycemic targets and improvements in the identification of hypoglycemic events. In T2DM patients, the increased use of aggressive insulin therapy might be associated with an increased risk of hypoglycemia, but comparison with previous trends is not possible owing to lack of reliable historical data. Rapidacting insulin analogues did not influence the frequency of severe hypoglycemia (74), whilst long-acting analogues seem to have some modest benefits in reducing the risk of nocturnal hypoglycemia (74). Recently, a new-generation ultra-long-acting basal insulin known as degludec was developed. This drug forms a depot of soluble multihexamers upon s.c. injection, from which insulin monomers are slowly and continuously absorbed into the blood with a flat profile and a more predictable glucose-lowering effect lasting beyond $42 \mathrm{~h}$ (75). In advanced T2DM patients, the use of insulin degludec resulted in long- 


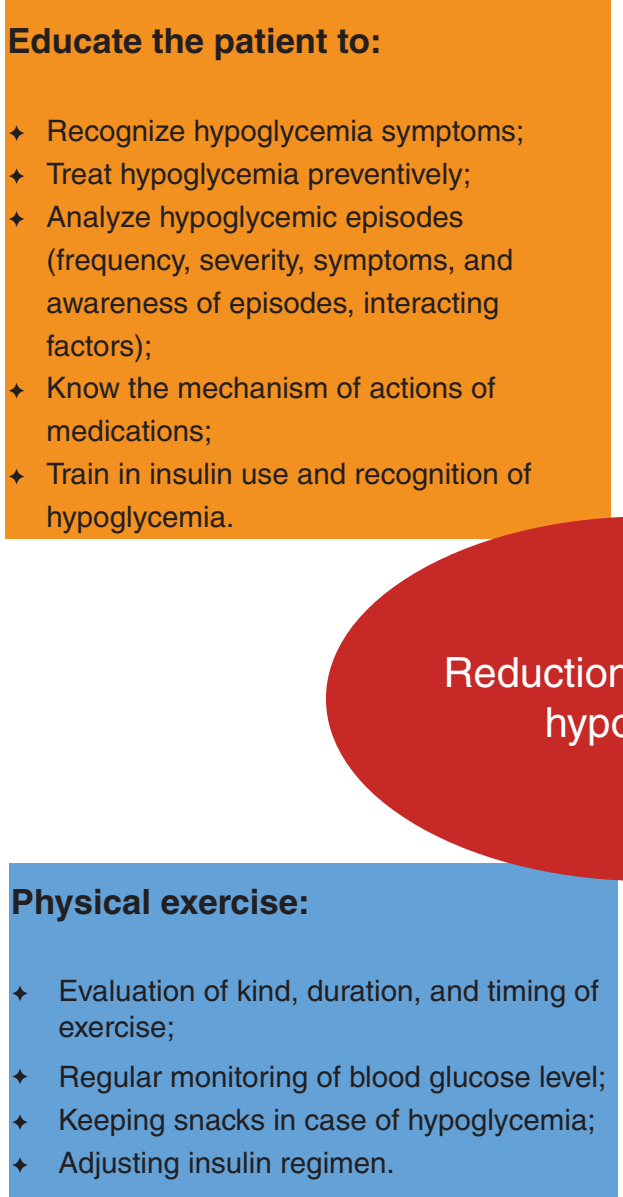

\section{Indicate dietary measures:}

Knowing carbohydrate content of foods;

Planning meals;

Modifying insulin regimen in a flexible way;

Ingesting fast-acting carbohydrate in the event of hypoglycemia. term improvements in glycemic control similar to those of patients treated with insulin glargine at similar doses, but with lower risks of overall (24\% lower) and nocturnal confirmed hypoglycemia (31\% lower) (76).

The frequency of hypoglycemia with new GLDs, such as incretins and SGLT2 inhibitors, is very low (77). Results of some trials indicated the efficacy of dipeptidyl peptidase (DPP)-4 inhibitors in improving glycemic control along with a low risk of hypoglycemia (both as a monotherapy and combined with insulin-sensitizing agents) and neutral effect on body weight (78). No increase in the risk of pancreatitis and pancreatic endocrine tumors in patients using these therapies has been demonstrated (79). Furthermore, a great body of literature has been published reporting that DPP-4 inhibitors provide a reasonable therapeutic alternative for elderly people with DM, leading to a significant improvement in glycemic control, with a low risk of hypoglycemia at least while used in monotherapy or in combination with insulin sensitizers together with a safety profile similar to placebo and a potentially better tolerability with respect to metformin $(80,81)$. Finally, these advantages were highlighted also in diabetic patients during Ramadan, for whom the available data indicate that DPP-4 inhibitors could be used rather than SUs for fewer hypoglycemic episodes and a greater reduction in weight and possibly $\mathrm{HbA1c}$ concentration (82). The increasing use of these agents will potentially help reduce the risk of hypoglycemia and its consequences, particularly among vulnerable patients, but the main barrier to their ordinary utilization is the cost.

\section{Future perspectives}

Continuous glucose monitoring (CGM) allows a better recognition of hypoglycemia during the night in patients with IAH and also of the wide glycemic fluctuations

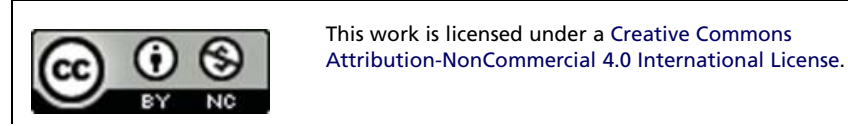


during the day (83). Given the increasing reliability and sensitivity of these devices, coupled with sensors and alarms, CGM could permit the eradication of unpredictable and incipient hypoglycemia.

Although there is no overall consensus, it is widely accepted that patients with frequent and severe hypoglycemia and/or IAH may benefit from continuous s.c. insulin infusion (CSII) $(84,85)$, reducing the rate of severe and moderate hypoglycemia over a 6-month period, with no change in HbA1C (86).

Intrahepatic islet transplantation has been demonstrated to restore glucose counter-regulation and improve hypoglycemia symptom recognition in long-standing T1DM patients, though the immunosuppression-related adverse effects should be considered (87). Using CGM systems, it was confirmed that transplant recipients had significantly decreased (in insulin-requiring subjects) or completely eradicated (in insulin-independent subjects) periods under hypoglycemia (88). This great reduction in the incidence of hypoglycemia was due to the marked reduction in exogenous insulin administration, the partial restoration of the glucagon counter-regulatory response, and the recovery of sympatho-adrenal response and hypoglycemia awareness $(89,90)$. For patients suffering from intractable, recurrent, severe hypoglycemia, wholepancreas or islet cell transplantation should be considered as a viable therapeutic option.

Since $\mathrm{K}_{\mathrm{ATP}}$ channels are involved in detection of hypoglycemia and the subsequent counter-regulatory response (91), recently the $\mathrm{K}_{\mathrm{ATP}}$ channel opener diazoxyde has been shown to increase the magnitude of the hormonal counter-regulatory response in long-standing T1DM patients with IAH (92).

\section{Conclusions}

Given the elevated risk of hypoglycemia among diabetic patients, preventing them from the achievement of good glycemic control, it is necessary to make a special effort to tailor therapy for each patient (63). Hypoglycemia is known to cause severe $\mathrm{CV}$ and neurological manifestations affecting the ordinary life and the quality of life of patients. A lower HbA1c, even delaying microvascular complications, can cause serious hypoglycemic episodes, mainly in the elderly and in people with HAAF. On the other hand, the achievement of a good HbA1c, preserving awareness of hypoglycemia, can be obtained by markedly reducing hypoglycemic episodes. Besides the precise choice of drugs, it is fundamental to advise patients to follow a balanced diet and perform regular self- monitoring of blood glucose, the latter being useful to warn patients in case of incipient hypoglycemia. Intensive glycemic control has two sides: the upside is partial prevention or delay of microvascular complications, while the downside is morbidity and potential mortality due to IAH. Therefore, a reasonable individualized glycemic goal is the lowest HbA1c that does not cause severe hypoglycemia and preserves awareness of hypoglycemia, preferably with little or no symptomatic or even asymptomatic hypoglycemia at a given stage in the evolution of the individual's diabetes. In order to do that, new GLDs and new types of insulin will help treat DM without or with fewer hypoglycemic events, reducing this huge burden of DM therapy.

\section{Declaration of interest}

The authors declare that there is no conflict of interest that could be perceived as prejudicing the impartiality of this review.

\section{Funding}

This work was supported by Grants from Swiss National Science Foundation to Dr F Montecucco (\#310030_152639/1), from the Foundation GerbexBourget, and the Progetti di Ricerca di Ateneo (PRA) Grant of the University of Genoa (Italy) to Dr F Montecucco.

\section{References}

1 Mühlhauser I, Overmann H, Bender R, Bott U \& Berger M. Risk factors of severe hypoglycaemia in adult patients with type I diabetes - a prospective population based study. Diabetologia 199841 1274-1282. (doi:10.1007/s001250051065)

2 UK Hypoglycaemia Study Group. Risk of hypoglycaemia in types 1 and 2 diabetes: effects of treatment modalities and their duration. Diabetologia 200750 1140-1147. (doi:10.1007/s00125-007-0599-y)

3 Jørgensen HV, Pedersen-Bjergaard U, Rasmussen AK \& BorchJohnsen K. The impact of severe hypoglycemia and impaired awareness of hypoglycemia on relatives of patients with type 1 diabetes. Diabetes Care 200326 1106-1109. (doi:10.2337/diacare.26.4.1106)

4 Pramming S, Thorsteinsson B, Bendtson I \& Binder C. Symptomatic hypoglycaemia in 411 type 1 diabetic patients. Diabetic Medicine 19918 217-222. (doi:10.1111/j.1464-5491.1991.tb01575.x)

5 Pedersen-Bjergaard U, Pramming S, Heller SR, Wallace TM, Rasmussen AK, Jørgensen HV, Matthews DR, Hougaard P \& Thorsteinsson B. Severe hypoglycaemia in 1076 adult patients with type 1 diabetes: influence of risk markers and selection. Diabetes/Metabolism Research and Reviews 200420 479-486. (doi:10.1002/dmrr.482)

6 Donnelly LA, Morris AD, Frier BM, Ellis JD, Donnan PT, Durrant R, Band MM, Reekie G \& Leese GP. DARTS/MEMO Collaboration. Frequency and predictors of hypoglycaemia in type 1 and insulintreated type 2 diabetes: a population-based study. Diabetic Medicine 200522 749-755. (doi:10.1111/j.1464-5491.2005.01501.x)

7 Östenson CG, Geelhoed-Duijvestijn P, Lahtela J, Weitgasser R, Markert Jensen M \& Pedersen-Bjergaard U. Self-reported non-severe hypoglycaemic events in Europe. Diabetic Medicine 201431 92-101. (doi:10.1111/dme.12261) 
8 Nielsen LR, Pedersen-Bjergaard U, Thorsteinsson B, Johansen M, Damm P \& Mathiesen ER. Hypoglycemia in pregnant women with type 1 diabetes: predictors and role of metabolic control. Diabetes Care 200831 9-14. (doi:10.2337/dc07-1066)

9 Henderson JN, Allen KV, Deary IJ \& Frier BM. Hypoglycaemia in insulin-treated type 2 diabe tes: frequency, symptoms and impaired awareness. Diabetic Medicine 200320 1016-1021. (doi:10.1046/j.1464-5491.2003.01072.x)

10 Workgroup on Hypoglycemia, American Diabetes Association. Defining and reporting hypoglycemia in diabetes: a report from the American Diabetes Association Workgroup on Hypoglycemia. Diabetes Care 200528 1245-1249. (doi:10.2337/diacare.28.5.1245)

11 European Medicines Agency Committee for Medicinal Products for Human Use (CHMP). Guideline on clinical investigation of medicinal products in the treatment or prevention of diabetes mellitus. CPMP/EWP/1080/00. Rev. 1 2012. http://www.ema.europa.eu/docs/ en_GB/document_library/Scientific_guideline/2012/06/ WC500129256.pdf (accessed February 2013).

12 Seaquist ER, Anderson J, Childs B, Cryer P, Dagogo-Jack S, Fish L, Heller SR, Rodriguez H, Rosenzweig J \& Vigersky R. Hypoglycemia and diabetes: a report of a workgroup of the American Diabetes Association and The Endocrine Society. Diabetes Care 201336 1384-1395. (doi:10.2337/dc12-2480)

13 Canadian Diabetes Association Clinical Practice Guidelines Expert Committee, Clayton D, Woo V \& Yale JF. Hypoglycemia. Canadian Journal of Diabetes 201337 (Suppl 1) S69-S71. (doi:10.1016/j.jcjd.2013. 01.022)

14 Amiel SA, Sherwin RS, Simonson DC \& Tamborlane WV. Effect of intensive insulin therapy on glycemic thresholds for counterregulatory hormone release. Diabetes 198837 901-907. (doi:10.2337/diab.37.7.901)

15 Davis SN, Shavers C, Mosqueda-Garcia R \& Costa F. Effects of differing antecedent hypoglycemia on subsequent counterregulation in normal humans. Diabetes 199746 1328-1335. (doi:10.2337/diab.46.8.1328)

16 Heller SR \& Cryer PE. Reduced neuroendocrine and symptomatic responses to subsequent hypoglycemia after 1 episode of hypoglycemia in nodiabetic humans. Diabetes 199140 223-226. (doi:10.2337/diab. 40.2.223)

17 Boyle PJ, Schwartz NS, Shah SD, Clutter WE \& Cryer PE. Plasma glucose concentrations at the onset of hypoglycemic symptoms in patients with poorly controlled diabetes and in nondiabetics. New England Journal of Medicine 1988318 1487-1492. (doi:10.1056/ NEJM198806093182302)

18 Mitrakou A, Ryan C, Veneman T, Mokan M, Jenssen T, Kiss I, Durrant J, Cryer P \& Gerich J. Hierarchy of glycemic thresholds for counterregulatory hormone secretion, symptoms, and cerebral dysfunction. American Journal of Physiology 1991260 E67-E74.

19 Frier BM \& Fisher BM. Impaired hypoglycaemia awareness. In Hypoglycaemia in Clinical Diabetes, pp 111-146. Eds BM Frier \& BM Fisher, Chichester: John Wiley and Sons, 1999.

20 Zammitt NN \& Frier BM. Hypoglycemia in type 2 diabetes: pathophysiology, frequency, and effects of different treatment modalities. Diabetes Care 200528 2948-2961. (doi:10.2337/diacare.28.12.2948)

21 Cryer PE, Davis SN \& Shamoon H. Hypoglycemia in diabetes. Diabetes Care 200326 1902-1912. (doi:10.2337/diacare.26.6.1902)

22 Graveling AJ \& Frier BM. Hypoglycaemia: an overview. Primary Care Diabetes 20093 131-139. (doi:10.1016/j.pcd.2009.08.007)

23 Fukuda M, Tanaka A, Tahara Y, Ikegami H, Yamamoto Y, Kumahara Y \& Shima K. Correlation between minimal secretory capacity of pancreatic $\beta$-cells and stability of diabetic control. Diabetes 198837 81-88. (doi:10.2337/diab.37.1.81)

24 Banarer S, McGregor VP \& Cryer PE. Intraislet hyperinsulinemia prevents the glucagon response to hypoglycemia despite an intact autonomic response. Diabetes 200251 958-965. (doi:10.2337/diabetes.51.4.958)

25 Segel SA, Paramore DS \& Cryer PE. Hypoglycemia-associated autonomic failure in advanced type 2 diabetes. Diabetes 200251 724-733. (doi:10.2337/diabetes.51.3.724)
26 Murad MH, Coto-Yglesias F, Wang AT, Sheidaee N, Mullan RJ, Elamin MB, Erwin PJ \& Montori VM. Clinical review: drug-induced hypoglycemia: a systematic review. Journal of Clinical Endocrinology and Metabolism 200994 741-745. (doi:10.1210/jc.2008-1416)

27 Parekh TM, Raji M, Lin YL, Tan A, Kuo YF \& Goodwin JS. Hypoglycemia after antimicrobial drug prescription for older patients using sulfonylureas. JAMA Internal Medicine 2014174 1605-1612. (doi:10.1001/jamainternmed.2014.3293)

28 Cryer PE. Hypoglycaemia: the limiting factor in the glycaemic management of type I and type II diabetes. Diabetologia 200245 937-948. (doi:10.1007/s00125-002-0822-9)

29 Davis TM, Brown SG, Jacobs IG, Bulsara M, Bruce DG \& Davis WA. Determinants of severe hypoglycemia complicating type 2 diabetes: the Fremantle diabetes study. Journal of Clinical Endocrinology and Metabolism 201095 2240-2247. (doi:10.1210/jc.2009-2828)

30 Amiel SA, Dixon T, Mann R \& Jameson K. Hypoglycaemia in type 2 diabetes. Diabetic Medicine 200825 245-254. (doi:10.1111/j.1464-5491. 2007.02341.x)

31 Katon WJ, Young BA, Russo J, Lin EH, Ciechanowski P, Ludman EJ \& Von Korff MR. Association of depression with increased risk of severe hypoglycemic episodes in patients with diabetes. Annals of Family Medicine 201311 245-250. (doi:10.1370/afm.1501)

32 Cryer PE. Mechanisms of hypoglycemia-associated autonomic failure in diabetes. New England Journal of Medicine 2013369 362-372. (doi:10.1056/NEJMra1215228)

33 Fanelli CG, Epifano L, Rambotti AM, Pampanelli S, Di Vincenzo A, Modarelli F, Lepore M, Annibale B, Ciofetta M, Bottini P et al. Meticulous prevention of hypoglycemia normalizes the glycemic thresholds and magnitude of most of neuroendocrine responses to, symptoms of, and cognitive function during hypoglycemia in intensively treated patients with short-term IDDM. Diabetes 199342 1683-1689. (doi:10.2337/diab.42.11.1683)

34 De Galan BE, Schouwenberg BJ, Tack CJ \& Smits P. Pathophysiology and management of recurrent hypoglycaemia and hypoglycaemia unawareness in diabetes. Netherlands Journal of Medicine $2006 \mathbf{6 4}$ 269-279.

35 White JR Jr. The contribution of medications to hypoglycemia unawareness. Diabetes Spectrum 200720 77-80. (doi:10.2337/ diaspect.20.2.77)

36 Ritholz MD \& Jacobson AM. Living with hypoglycemia. Journal of General Internal Medicine 199813 799-804. (doi:10.1046/j.1525-1497. 1998.00243.x)

37 Rubin RR \& Peyrot M. Psychological issues and treatments for people with diabetes. Journal of Clinical Psychology 200157 457-478. (doi:10.1002/jclp.1041)

38 Inkster B \& Frier BM. Diabetes and driving. Diabetes, Obesity \& Metabolism 201315 775-783. (doi:10.1111/dom.12071)

39 Gogitidze Joy N, Hedrington MS, Briscoe VJ, Tate DB, Ertl AC \& Davis SN. Effects of acute hypoglycemia on inflammatory and pro-atherothrombotic biomarkers in individuals with type 1 diabetes and healthy individuals. Diabetes Care 201033 1529-1535. (doi:10.2337/dc09-0354)

40 Schwartz NS, Clutter WE, Shah SD \& Cryer PE. Glycemic thresholds for activation of glucose counterregulatory systems are higher than the threshold for symptoms. Journal of Clinical Investigation $1987 \mathbf{7 9}$ 777-781. (doi:10.1172/JCI112884)

41 Wright RJ, Newby DE, Stirling D, Ludlam CA, Macdonald IA \& Frier BM. Effects of acute insulin-induced hypoglycemia on indices of inflammation: putative mechanism for aggravating vascular disease in diabetes. Diabetes Care 201033 1591-1597. (doi:10.2337/dc10-0013)

42 Wright RJ \& Frier BM. Vascular disease and diabetes: is hypoglycaemia an aggravating factor? Diabetes/Metabolism Research and Reviews 2008 24 353-363. (doi:10.1002/dmrr.865)

43 Collier A, Patrick AW, Hepburn DA, Bell D, Jackson M, Dawes J \& Frier BM. Leucocyte mobilization and release of neutrophil elastase following acute insulin-induced hypoglycaemia in normal humans.

\section{This work is licensed under a Creative Commons


Diabetic Medicine 19907 506-509. (doi:10.1111/j.1464-5491.1990. tb01432.x)

44 Corrall RJ, Webber RJ \& Frier BM. Increase in coagulation factor VIII activity in man following acute hypoglycaemia: mediation via an adrenergic mechanism. British Journal of Haematology 198044 301-305. (doi:10.1111/j.1365-2141.1980.tb01212.x)

45 Chow EYK, Iqbal A, Phoenix F, Heller SR \& Ajjan RA. Hypoglycaemia promotes thrombosis and inflammation for at least one week in patients with type 2 diabetes. Diabetologia 201356 (Suppl 1) S243. (doi:10.1007/s00125-013-3012-z)

46 Sommerfield AJ, Wilkinson IB, Webb DJ \& Frier BM. Vessel wall stiffness in type 1 diabetes and the central hemodynamic effects of acute hypoglycemia. American Journal of Physiology. Endocrinology and Metabolism 2007293 E1274-E1279. (doi:10.1152/ajpendo.00114.2007)

47 Rana O, Byrne CD, Kerr D, Coppini DV, Zouwail S, Senior R, Begley J, Walker JJ \& Greaves K. Acute hypoglycemia decreases myocardial blood flow reserve in patients with type 1 diabetes mellitus and in healthy humans. Circulation 2011124 1548-1556. (doi:10.1161/ CIRCULATIONAHA.110.992297)

48 Koivikko ML, Karsikas M, Salmela PI, Tapanainen JS, Ruokonen A, Seppänen T, Huikuri HV \& Perkiömäki JS. Effects of controlled hypoglycaemia on cardiac repolarisation in patients with type 1 diabetes. Diabetologia 200851 426-435. (doi:10.1007/s00125007-0902-y)

49 Robinson RT, Harris ND, Ireland RH, Lee S, Newman C \& Heller SR. Mechanisms of abnormal cardiac repolarization during insulininduced hypoglycemia. Diabetes 200352 1469-1474. (doi:10.2337/ diabetes.52.6.1469)

50 Rothenbuhler A, Bibal CP, Le Fur S \& Bougneres P. Effects of a controlled hypoglycaemia test on QTc in adolescents with type 1 diabetes. Diabetic Medicine 200825 1483-1485. (doi:10.1111/j. 1464-5491.2008.02599.x)

51 Laitinen T, Lyyra-Laitinen T, Huopio H, Vauhkonen I, Halonen T, Hartikainen J, Niskanen L \& Laakso M. Electrocardiographic alterations during hyper- insulinemic hypoglycemia in healthy subjects. Annals of Noninvasive Electrocardiology 200813 97-105. (doi:10.1111/ j.1542-474X.2008.00208.x)

52 Beom JW, Kim JM, Chung EJ, Kim JY, Ko SY, Na SD, Kim CH, Park G \& Kang MY. Corrected QT interval prolongation during severe hypoglycemia without hypokalemia in patients with type 2 diabetes. Diabetes \& Metabolism Journal 201337 190-195. (doi:10.4093/dmj.2013.37.3.190)

53 Lee SA, Cho SJ, Jeong MH, Kim YJ, Kim CJ, Cho MC, Kim HS, Ahn Y, Koh G, Lee JM et al. Hypoglycemia at admission in patients with acute myocardial infarction predicts a higher 30-day mortality in patients with poorly controlled type 2 diabetes than in well-controlled patients. Diabetes Care 201437 2366-2373. (doi:10.2337/dc13-2856)

54 Chow E, Bernjak A, Williams S, Fawdry RA, Hibbert S, Freeman J, Sheridan PJ \& Heller SR. Risk of cardiac arrhythmias during hypoglycemia in patients with type 2 diabetes and cardiovascular risk. Diabetes 201463 1738-1747. (doi:10.2337/db13-0468)

55 Banarer S \& Cryer PE. Sleep-related hypoglycemia-associated autonomic failure in type 1 diabetes: reduced awakening from sleep during hypoglycemia. Diabetes 200352 1195-1203. (doi:10.2337/ diabetes.52.5.1195)

56 Inkster B \& Frier BM. The effects of acute hypoglycaemia on cognitive function in type 1 diabetes. British Journal of Diabetes and Vascular Disease 201212 221-226. (doi:10.1177/1474651412466273)

57 Warren RE \& Frier BM. Hypoglycaemia and cognitive function. Diabetes, Obesity \& Metabolism 20057 493-503. (doi:10.1111/ j.1463-1326.2004.00421.x)

58 Zammitt NN, Warren RE, Deary IJ \& Frier BM. Delayed recovery of cognitive function following hypoglycemia in adults with type 1 diabetes: effect of impaired awareness of hypoglycemia. Diabetes 2008 57 732-736. (doi:10.2337/db07-0695)

59 Perros P \& Bjørgaas M. Neurological sequelae of hypoglycaemia. In Hypoglycaemia in Clinical Diabetes, ch 15, 3rd edn, pp 305-322.
Eds BM Frier, SR Heller \& RJ McCrimmon. Chichester: Wiley Blackwell, 2014. (doi:10.1002/9781118695432.ch15)

60 Kennan RP, Takahashi K, Pan C, Shamoon H \& Pan JW. Human cerebral blood flow and metabolism in acute insulin-induced hypoglycemia. Journal of Cerebral Blood Flow and Metabolism 200525 527-534. (doi:10.1038/sj.jcbfm.9600045)

61 MacLeod KM, Gold AE, Ebmeier KP, Hepburn DA, Deary IJ, Goodwin GM \& Frier BM. The effects of acute hypoglycemia on relative cerebral blood flow distribution in patients with type I (insulindependent) diabetes and impaired hypoglycemia awareness. Metabolism 199645 974-980. (doi:10.1016/S0026-0495(96)90266-8)

62 Zammitt NN \& Frier BM. Hypoglycaemia in type 2 diabetes and in elderly people. In Hypoglycaemia in Clinical Diabetes, ch 12, 3rd edn, pp 230-262. Eds BM Frier, SR Heller \& RJ McCrimmon RJ. Chichester: Wiley Blackwell, 2014. (doi:10.1002/9781118695432.ch12)

63 Inzucchi SE, Bergenstal RM, Buse JB, Diamant M, Ferrannini E, Nauck M, Peters AL, Tsapas A, Wender R \& Matthews DR. Management of hyperglycaemia in type 2 diabetes 2015: a patient-centred approach. Update to a position statement of the American Diabetes Association and the European Association for the Study of Diabetes. Diabetologia 201558 429-442. (doi:10.1007/s00125-014-3460-0)

64 Seaquist ER, Anderson J, Childs B, Cryer P, Dagogo-Jack S, Fish L, Heller SR, Rodriguez H, Rosenzweig J \& Vigersky R. Hypoglycemia and diabetes: a report of a workgroup of the American Diabetes Association and the Endocrine Society. Diabetes Care 201336 1384-1395. (doi:10.2337/dc12-2480)

65 Dailey G. Assessing glycemic control with self-monitoring of blood glucose and hemoglobin $\mathrm{A}_{1 \mathrm{c}}$ measurements. Mayo Clinic Proceedings 200782 229-235; quiz 236. (doi:10.1016/S0025-6196(11)61003-3)

66 Klonoff DC, Blonde L, Cembrowski G, Chacra AR, Charpentier G, Colagiuri S, Dailey G, Gabbay RA, Heinemann L, Kerr D et al. Consensus report: the current role of self-monitoring of blood glucose in noninsulin-treated type 2 diabetes. Journal of Diabetes Science and Technology 20115 1529-1548. (doi:10.1177/193229681100500630)

67 Polonsky WH, Fisher L, Schikman CH, Hinnen DA, Parkin CG, Jelsovsky Z, Petersen B, Schweitzer M \& Wagner RS. Structured selfmonitoring of blood glucose significantly reduces A1C levels in poorly controlled, noninsulin-treated type 2 diabetes: results from the Structured Testing Program study. Diabetes Care 201134 262-267. (doi:10.2337/dc10-1732)

68 Graveling AJ \& Frier BM. Impaired awareness of hypoglycaemia: a review. Diabetes \& Metabolism 201036 (Suppl 3) S64-S74. (doi:10.1016/ S1262-3636(10)70470-5)

69 Cox DJ, Gonder-Frederick L, Ritterband L, Clarke W \& Kovatchev BP. Prediction of severe hypoglycemia. Diabetes Care 200730 1370-1373. (doi:10.2337/dc06-1386)

70 Cox DJ, Kovatchev B, Koev D, Koeva L, Dachev S, Tcharaktchiev D, Protopopova A, Gonder-Frederick L \& Clarke W. Hypoglycemia anticipation, awareness and treatment training (HAATT) reduces occurrence of severe hypoglycemia among adults with type 1 diabetes mellitus. International Journal of Behavioral Medicine 200411 212-218. (doi:10.1207/s15327558ijbm1104_4)

71 Sämann A, Mühlhauser I, Bender R, Kloos Ch \& Müller UA. Glycaemic control and severe hypoglycaemia following training in flexible, intensive insulin therapy to enable dietary freedom in people with type 1 diabetes: a prospective implementation study. Diabetologia 2005 48 1965-1970.

72 Hopkins D, Lawrence I, Mansell P, Thompson G, Amiel S, Campbell M \& Heller S. Improved biomedical and psychological outcomes 1 year after structured education in flexible insulin therapy for people with type 1 diabetes: the U.K. DAFNE experience. Diabetes Care 201235 1638-1642. (doi:10.2337/dc11-1579)

73 Kristensen PL, Hansen LS, Jespersen MJ, Pedersen-Bjergaard U, Beck-Nielsen H, Christiansen JS, Nørgaard K, Perrild H, Parving HH, Thorsteinsson $\mathrm{B}$ et al. Insulin analogues and severe hypoglycaemia in 
type 1 diabetes. Diabetes Research and Clinical Practice 201296 17-23. (doi:10.1016/j.diabres.2011.10.046)

74 Siebenhofer A, Plank J, Berghold A, Narath M, Gfrerer R \& Pieber TR. Short acting insulin analogues versus regular human insulin in patients with diabetes mellitus. Cochrane Database of Systematic Reviews 2006. CD003287. (doi:10.1002/14651858.CD003287.pub4)

75 Heise T, Hermanski L, Nosek L, Feldman A, Rasmussen S \& Haahr H. Insulin degludec: four times lower pharmacodynamic variability than insulin glargine under steady-state conditions in type 1 diabetes. Diabetes, Obesity \& Metabolism 201214 859-864. (doi:10.1111/j.14631326.2012.01627.x)

76 Hollander P, King AB, Del Prato S, Sreenan S, Balci MK, MuñozTorres M, Rosenstock J, Hansen CT, Niemeyer M \& Garber AJ. Insulin degludec improves long-term glycaemic control similarly to insulin glargine but with fewer hypoglycaemic episodes in patients with advanced type 2 diabetes on basal-bolus insulin therapy. Diabetes, Obesity \& Metabolism 201517 202-206. (doi:10.1111/dom.12411)

77 Inkster B, Zammitt NN \& Frier BM. Drug-induced hypoglycaemia in type 2 diabetes. Expert Opinion on Drug Safety 201211 597-614. (doi:10.1517/14740338.2012.694424)

78 Aroda VR, Henry RR, Han J, Huang W, DeYoung MB, Darsow T \& Hoogwerf BJ. Efficacy of GLP-1 receptor agonists and DPP-4 inhibitors: meta-analysis and systematic review. Clinical Therapeutics 201234 1247-1258. (doi:10.1016/j.clinthera.2012.04.013)

79 Monami M, Dicembrini I \& Mannucci E. Dipeptidyl peptidase-4 inhibitors and pancreatitis risk: a meta-analysis of randomized clinical trials. Diabetes, Obesity \& Metabolism 201416 48-56. (doi:10.1111/dom.12176)

80 Avogaro A, Dardano A, de Kreutzenberg SV \& Del Prato S. Dipeptidyl peptidase- 4 inhibitors can minimize the hypoglycaemic burden and enhance safety in elderly people with diabetes. Diabetes, Obesity \& Metabolism 201517 107-115. (doi:10.1111/dom.12319)

81 Schwarz SL. Treatment of elderly patients with type 2 diabetes mellitus: a systematic review of the benefits and risks of dipeptidyl peptidase- 4 inhibitors. American Journal of Geriatric Pharmacotherapy 20108 405-418. (doi:10.1016/j.amjopharm.2010.10.003)

82 Gray LJ, Dales J, Brady EM, Khunti K, Hanif W \& Davies MJ. Safety and effectiveness of non-insulin glucose-lowering agents in the treatment of people with type 2 diabetes who observe Ramadan: a systematic review and meta-analysis. Diabetes, Obesity \& Metabolism 201517 639-648. (doi:10.1111/dom.12462)
83 Choudhary P, Ramasamy S, Green L, Gallen G, Pender S, Brackenridge A, Amiel SA \& Pickup JC. Real-time continuous glucose monitoring significantly reduces severe hypoglycemia in hypoglycemia-unaware patients with type 1 diabetes. Diabetes Care 201336 4160-4162. (doi:10.2337/dc13-0939)

84 Hanaire H, Lassmann-Vague V, Jeandidier N, Renard E, Tubiana-Rufi N, Vambergue A, Raccah D, Pinget M \& Guerci B. Treatment of diabetes mellitus using an external insulin pump: the state of the art. Diabetes \& Metabolism 200834 401-423. (doi:10.1016/S1262-3636(08)73972-7)

85 Vigersky RA. The benefits, limitations, and cost-effectivenes of advanced technologies in the management of patients with diabetes mellitus. Journal of Diabetes Science and Technology 20159 320-330. (doi:10.1177/1932296814565661)

86 Ly TT, Nicholas JA, Retterath A, Lim EM, Davis EA \& Jones TW. Effect of sensor-augmented insulin pump therapy and automated insulin suspension vs standard insulin pump therapy on hypoglycemia in patients with type 1 diabetes: a randomized clinical trial. Journal of the American Medical Association 2013310 1240-1247. (doi:10.1001/jama. 2013.277818)

87 Rickels MR, Fuller C, Dalton-Bakes C, Markmann E, Palanjian M, Cullison K, Tiao J, Kapoor S, Liu C, Naji A et al. Restoration of glucose counterregulation by islet transplantation in long-standing type 1 diabetes. Diabetes 201564 1713-1718. (doi:10.2337/db14-1620)

88 Paty BW, Senior PA, Lakey JR, Shapiro AM \& Ryan EA. Assessment of glycemic control after islet transplantation using the continuous glucose monitor in insulin-independent versus insulin-requiring type 1 diabetes subjects. Diabetes Technology \& Therapeutics 20068 165-173. (doi:10.1089/dia.2006.8.165)

89 Leitão CB, Tharavanij T, Cure P, Pileggi A, Baidal DA, Ricordi C \& Alejandro R. Restoration of hypoglycemia awareness after islet transplantation. Diabetes Care 200831 2113-2115. (doi:10.2337/dc08-074)

90 Rickels MR. Recovery of endocrine function after islet and pancreas transplantation. Current Diabetes Reports 201212 587-596. (doi:10.1007/s11892-012-0294-3)

91 Ashford ML, Boden PR \& Treherne JM. Glucose-induced excitation of hypothalamic neurones is mediated by ATP-sensitive $\mathrm{K}^{+}$channels Pflügers Archiv : European Journal of Physiology 1990415 479-483. (doi:10.1007/BF00373626)

92 George PS, Tavendale R, Palmer CN \& McCrimmon RJ. Diazoxide improves hormonal counterregulatory responses to acute hypoglycemia in long-standing type 1 diabetes. Diabetes 201564 2234-2241. (doi:10.2337/db14-1539)

Received in final form 5 June 2015

Accepted 19 June 2015 http://www.endocrineconnections.org DOI: 10.1530/EC-15-0044
(C) 2015 The authors Published by Bioscientifica Ltd
This work is licensed under a Creative Commons Attribution-NonCommercial 4.0 International License. 